Interdisciplinary Bomminases of law V1 N.1 2019

http://dx.doi.org/10.23925/2596-3333.2019v1i1a12

\title{
AÇÃO CIVIL EX DELICTO E AS EXCLUDENTES DE ILICITUDE PREVISTOS NO artigo 23 do Código Penal
}

Pedro Henrique Santos Passos GraduAndo EM Direito Na Universidade DE Minas

RESUMO: O presente artigo aborda as hipóteses de aplicação da ação civil ex delicto, bem como, suas especificações. Serão estudados os institutos que excluem a responsabilidade civil como também as suas exceções e possibilidades de regresso.

Palavras Chave: RESPONSABILIDADE. EXCLUDENTES DE ILICITUDE. AÇÃO CIVIL EX DELICTO.

\section{CiVIL ACTION EX DELICTO AND THE EXCLUSIONS OF UNLAWFULNESS FORESEen In ARTICle 23 OF THE PenAl Code}

ABSTRACT: This article deals with the hypothesis of applying the civil action ex delicto, as well as its specifications. The institutes that exclude civil liability will be studied as well as their exceptions and possibilities of return.

KEYWORDS: RESPONSIBILITY. EXCLUSION OF UNLAWFULNESS. CIVIL ACTION EX DELICTO.

\section{INTRODUÇÃO}

Com a sentença penal condenatória transitado em julgado surge uma pretensão indenizatória, nesse sentido, a ação civil ex delicto possui a finalidade de buscar uma indenização pelo dano sofrido, cuja causa de pedir é o ilícito criminal. Dessa forma, o ofendido está habilitado a executá-la na esfera civil, com a finalidade de reparação do equilíbrio moral ou patrimonial que é causado por um ou mais autores.

Entretanto, o Código Civil e Penal apresenta exceções a essa regra, as chamadas excludentes de ilicitude, que devido sua natureza não será possível exercer o direito da referida ação. 


\section{/ Fronteiras Interdisciplinares do Direito \\ Interdisciplinary Boumdaries of Iaw V1N.12019}

Ao mesmo tempo, esse trabalho tem por finalidade analisar as causas de excludentes de ilicitude no âmbito geral e específico de modo que em determinados casos, surgirá ao terceiro o direito de regresso.

\section{CONSIDERAÇÕES ACERCA DA AÇÃO CIVIL EX DELICTO}

\subsection{CONCEITO}

A ação civil ex delicto é uma ação ajuizada pelo ofendido na esfera cível para obter indenização pelo dano causado pela infração penal. Assim, toda vez que se comete um ato ilícito penal, surge uma pretensão punitiva de ação penal, que enseja a aplicação de pena ou medida de segurança aos culpados, e em grande maioria das vezes, uma pretensão civil, a fim de se reparar o dano causado, a si ou a terceiros.

Na definição exposta pelo doutrinador Tourinho Filho, temos que:

Chama-se actio civilis ex delicto, o prejuízo (dano) sofrido pelo indivíduo através de um ilícito penal e não civil, desta forma, é a actio que o lesado pode entremear, visando à satisfação do prejuízo, uma vez que a causa pretendi, a razão em que existe o pedido é o fato criminoso. Isto é, a justificativa para ingressar com a Ação Civil ex delicto é a consequência trazida pelo ato ilícito descrito no Código Penal, a qual cria a responsabilidade pelo fato, oriunda do Direito Civil tendo como escopo "a satisfação do dano produzido pela infração". (TOURINHO, 2009, p. 258.)

Portanto, tal ação somente caberá nas hipóteses em que a repercussão da infração penal também atingir a esfera da responsabilidade civil.

\section{2. ОВJETO}

Ao tratar deste tipo de ação o Código de Processo Penal prevê meios mais eficientes para a vítima buscar a reparação. A satisfação do dano causado pode ocorrer através de quatro formas distintas. 


\section{( Fronteiras Interdisciplinares do Direito \\ Interdisciplinary Boundaries of law V1 N.12019}

A restituição é a espécie de reparação mais simples. Quando o dano for de natureza econômica, poderá o objeto constituir-se de uma restituição do bem apropriado indevidamente, de modo a recompô-lo patrimonialmente em decorrência da ilicitude também cível, por exemplo, em casos de furtos.

O ressarcimento constitui no pagamento do dano patrimonial, com o intuito de satisfazer os danos emergentes e os lucros cessantes.

A reparação será cabível quando o dano não for ressarcível em espécie, quando não puder ser estimado em dinheiro, devido sua natureza não patrimonial.

Por fim, a indenização consistirá em uma recomposição por falha de quem, em regra, não poderia errar. Figura como um meio de compensação por dano causado por ato ilícito praticado pelo Estado.

\subsection{LEGITIMIDADE}

Para propor uma ação civil ex delicto, possuem legitimidade ativa o ofendido, aquele que foi diretamente prejudicado pelo fato delituoso- seu representante legal e seus herdeiros como expressos no art. 63, caput, CPP.

Outrossim, quando o titular do direito de reparação do dano for pobre, na qual, não puder prover às despesas processuais sem privar-se dos recursos indispensáveis ao seu sustento e o sustento de sua família, o Ministério Público é o legitimado para propor a ação que visa tal reparação, conforme art. 68 do CPP.

\subsection{AUTONOMIA DE JURISDIÇÃo}

O nosso atual ordenamento pátrio traz a separação da jurisdição, ou seja, a ação penal tem por objetivo a condenação do agente com relação à infração penal, enquanto que a ação civil tem por finalidade a reparação do dano sofrida pelo ofendido.

Neste ponto, se faz pertinente salientar que a questão do sobrestamento está prevista no art. 64 do CPP: “intentada a ação penal, o juiz da ação civil poderá suspender o curso desta, até o julgamento definitivo daquela".

Nas palavras de Eugênio Pacelli:

(...) o vocábulo poderá, constante do citado art. 64, parágrafo único, do CPP, confere verdadeiro poder discricionário ao juiz do cível, acerca da conveniência da suspensão do processo naquela instância. 


\section{( Fronteiras Interdisciplinares do Direito}

Interdisciplinary Bomelaries of I aw V1 N.1 2019

(...) Isto porque, somente a partir do exame do estágio de desenvolvimento procedimental de um e outro processo (a ação cível e a penal) é que se poderá avaliar a conveniência de se suspender o processo no cível. Assim, quando já estiver encerrada a instrução na ação civil, não haverá, segundo nos parece, qualquer razão para a suspensão do processo se, por exemplo, estiver ainda no início do procedimento criminal. (...) Entretanto, se estiverem ambas as ações em fases procedimentais igualmente desenvolvidas, ou ainda quando a ação cível estiver mais adiantada, mas não concluída a sua fase instrutória, a suspensão do processo civil se revelará extremamente oportuna e conveniente, na medida em que determinadas questões, quando resolvidas no juízo criminal, subordinam o conteúdo da decisão a ser proferida no cível. (EUGÊNIO, 2010, p.312)

Nesse sentido, pode ocorrer a duplicidade de ações, uma na vara cível e outra na criminal, mas sempre evitando decisões contraditórias. O juiz da vara criminal pode estipular um valor mínimo para a restituição do dano, mas se houver sentença no cível com a liquidação do dano, aquele juiz deve se abster de fixar qualquer valor.

Vale ressaltar que não se pode entrar com ação civil ex delicto enquanto estiver correndo a ação penal, pois um dos principais requisitos dela é o título executivo decorrente de sentença penal transitada em julgado.

A esse respeito, Tourinho Filho assevera:

No Direito pátrio, o sistema adotado é o da independência, com certa mitigação. A parte interessada se quiser, poderá promover a ação para a satisfação do dano somente na sede civil; jamais ingressar em sede penal para postulá-la. Como o fato gerador dessas responsabilidades é o crime, se houver sentença penal condenatória com trânsito em julgado, em face da influência que tal decisão exerce no cível, será ela exequível na jurisdição civil, onde não mais se discutirá o an debeatur (se deve), e sim o quantum debeatur (quanto é devido). (TOURINHO, 2009, p. 261)

Portanto, a responsabilidade civil é independente da criminal à luz do art. 935 do Código Civil: "A responsabilidade civil é independente da criminal, não se podendo questionar mais sobre a existência do fato, ou sobre quem seja o seu autor, quando estas questões se acharem decididas no juízo criminal.”, e a condenação criminal torna certa a obrigação de indenizar o dano causado pelo criminal, art. 91, I, do Código Penal.

\subsection{Sentença Penal condenatória e Absolutória}




\section{( Fronteiras Interdisciplinares do Direito \\ Interdisciplinary Boundaries of law V1 N.12019}

Como já analisado anteriormente, no Brasil é adotado o sistema de independência e por mais que tente se alcançar uma única jurisdição, nem sempre as decisões prolatadas em uma esfera, aproveita-se em outra.

No que tange a sentença penal condenatória, conforme o art. 935 do Código Civil, uma vez comprovada no juízo criminal à existência do fato, bem como a sua autoria, estas questões não poderão ser mais discutidas na instância cível, ou seja, devido sua natureza subordinante, impedem a reabertura da discussão em outro processo.

Porém, ao se tratar nos possíveis casos diferentes do art. 935 do CC, Eugênio Pacelli de Oliveira:

É perfeitamente possível a alegação, no cível, da concorrência de culpa no evento danoso, ainda que tal questão não tenha sido abordada no juízo criminal, ou, se abordada, não tenha se mostrado suficiente para afastar a responsabilidade penal. (EUGÊNIO, 2010, p. 212)

No que diz respeito à sentença penal absolutória, uma vez provada a inexistência do fato e caso o juiz considerar que o réu não concorreu para a infração penal, não se poderá mais discutir tal questão no juízo cível, ou seja, não poderá a vítima propor ação civil ex delicto em conformidade com o disposto no art. 66 do CPP.

\section{EXCLUDENTES DE ILICITUDE}

O código Penal no art. 23 sustenta que não haverá crime quando o agente pratica o fato em estado de necessidade, legítima defesa, estrito cumprimento do dever legal e exercício regular do direito. Nesse sentido, o código de processo penal assegura que a sentença penal condenatória transitada em julgado que reconhecer alguma excludente de ilicitude também trará coisa julgada no civil, de acordo com o art. 65do CPP.

Embora expressamente exposto que as excludentes fazem coisa julgada no civil, existem exceções legais que dão abertura para discussões na esfera civil. Dentro dessa perspectiva, Eugênio Pacelli de Oliveira constata que:

Impõe-se registrar que, embora seja vedada a reabertura da discussão acerca da matéria então decidida (excludentes reais), a responsabilidade civil não será afastada quando houver expressado previsão legal neste sentido, ou seja, prevendo a recomposição do dano, mesmo nas hipóteses de legítima defesa, estado de necessidade, 


\section{/ Fronteiras Interdisciplinares do Direito}

Interdisciplinary Bomandaries of law V1 N.12019

estrito cumprimento do dever legal ou exercício regular do direito. (EUGÊNIO, 2010, p. 214).

Nota-se que esse assunto é âmbito de inúmeras discussões no meio jurídico e doutrinário, fazendo-se necessário uma abordagem mais específica e individualizada acerca destas causas legais de excludentes prevista no art. 23 do CP.

\subsection{ESTADO DE NECESSIDADE}

O próprio legislador definiu o estado de necessidade, no art. 24 do Código penal:

Considera-se em estado de necessidade quem pratica o fato para salvar de perigo atual, que não provocou por sua vontade, nem podia de outro modo evitar, direito próprio ou alheio, cujo sacrifício, nas circunstâncias, não era razoável exigir-se.

O mesmo possui previsão legal no art. 188 do Código Civil, Inciso II - “ $a$ deterioração ou destruição da coisa alheia, ou a lesão a pessoa, a fim de remover perigo iminente", ou seja, não é considerado ilícito o ato daquele em estado de necessidade, que ao encontrar em uma situação de perigo eminente, é obrigado a deteriorar ou destruir coisa alheia ou lesionar pessoa a fim de remover esse perigo.

Entretanto, os art. 929 e 930 do CC trazem respectivamente:

Art. 929. Se a pessoa lesada, ou o dono da coisa, no caso do inciso II do art. 188 , não forem culpados do perigo, assistir-lhes-á direito à indenização do prejuízo que sofreram.

Art. 930. No caso do inciso II do art. 188 , se o perigo ocorrer por culpa de terceiro, contra este terá o autor do dano ação regressiva para haver a importância que tiver ressarcido ao lesado.

Embora o ato não seja considerado ilícito, o Código Civil ampara os bens do terceiro uma indenização correspondente aos prejuízos causados. Esclarecendo o assunto, Rogério Greco nos diz que:

Mesmo que a conduta do agente que atua em estado de necessidade não seja ilícita, porque seria uma incongruência o Código Penal considerá-la licita, enquanto para o Código Civil seria ilícita, se o terceiro que sofreu com a conduta do agente não tiver sido o causador da situação de perigo, permanecerá a obrigação de indenizar os prejuízos causados. Caso o perigo tenha sido criado por aquele que sofreu o dano, não lhe caberá, aqui, o direito de 


\section{/ Fronteiras \\ Interdisciplinares \\ do Direito}

Interdisciplinamy Boundaries of law V1N.12019

indenização. Embora o agente tenha a obrigação de indenizar aquele que sofreu o dano com a sua conduta, se a situação de perigo tiver sido provocada por culpa de terceiro, ser-lhe-á permitida ação regressiva contra este, para haver a importância que tiver sido ressarcida ao dono da coisa (ROGÉRIO, 2017, p.443)

Logo, a pessoa lesada ou o dono da coisa que tiver sofrido algum dano necessário ao afastamento do perigo e não forem culpados, terão eles o direito à indenização e assegura o direito de regresso do agente causador do dano contra o terceiro que tenha dado causa a esse estado de perigo a fim de reaver o que gastou ressarcindo o lesado ou o dono da coisa.

\subsection{LEGÍTIMA DEFESA}

O Estado, como é conhecimento de todos, não pode estar em todos os lugares ao mesmo tempo, por isso, possibilita ao cidadão, em determinadas situações, agir em sua própria defesa. A legítima defesa é definida de acordo com a situação atual ou iminente de injusta agressão em que o agente poderá ser atingido tanto para si como para um terceiro. E em razão disso o agente irá agir de forma a repulsar os atos do autor.

Possui amparo legal no art. 188, do CC, inciso, "I - os praticados em legítima defesa ou no exercício regular de um direito reconhecido.", onde, aquele que atua em legítima defesa não pratica ato ilícito capaz de suportar a obrigação de indenizar.

Rogério Greco analisa da seguinte forma:

Aqui, temos em confronto um bem que se procura defender em face de uma injusta agressão contra ele praticada. Assim, prefere o ordenamento jurídico tutelar o bem injustamente agredido, e, se porventura o agressor vier a sofrer danos, não lhe caberá o direito de pedir indenização contra aquele que, defendendo licitamente seu bem ou interesse, fazendo cessar a injusta agressão que era levada a feito, com sua atitude causou danos no agressor. (REGÉRIO, 2017, p. 427)

Entretanto, existe uma exceção da legitima defesa, onde será necessária a reparação civil. Trata-se de legitima defesa com erro de execução. Diz o art. 73 do CP:

Art. 73 - Quando, por acidente ou erro no uso dos meios de execução, o agente, ao invés de atingir a pessoa que pretendia ofender, atinge pessoa diversa, responde como se tivesse praticado o crime contra aquela, atendendo-se ao disposto no $\S 3^{\circ}$ do art. 20 deste Código. No caso de ser também atingida a pessoa que o agente pretendia ofender, aplica-se a regra do art. 70 deste Código. 


\section{/ Fronteiras Interdisciplinares do Direito}

Interdisciplinary Boumdaries of law V1 N.12019

Esta hipótese pode ocorrer quando um determinado agente almejando repelir a injusta agressão, agindo com animus defendendi, acaba por ferir outra pessoa que não o seu agressor, ou até mesmo os dois, agressor e terceiro.

O resultado advindo da aberração no ataque, (aberratio ictus) seja, o ferimento ou a morte de terceiro e não seu agressor, este, estará amparado pela justificação da legitima defesa, assim, não podendo responder criminalmente.

Contudo, em relação ao terceiro inocente, cabe responsabilidade civil do agente. Assis Toledo afirma:

Não se aplica, pois, ao terceiro inocente a norma do art. 65 do Código de Processo Penal, já que, quanto a ele, a lesão, apesar da absolvição do agente, não pode ser considerada um ilícito civil. Trata-se, portanto, de uma hipótese em que a exclusão da responsabilidade penal não impede a afirmação da responsabilidade civil, restrita é claro ao terceiro inocente. (ASSIS, 1994, p.199)

Portanto, uma vez evidente que tenha ocorrido o erro de execução em face ao terceiro inocente, surge a este, a pretensão indenizatória a fim de pleitear direito acometido pelo agente.

\subsection{ESTRITO CUMPRIMENTO DE DEVER LEGAL}

Este, por sua vez, não teve seu conteúdo expresso no Código Civil, somente no Código Penal: Art. 23 - Não há crime quando o agente pratica o fato: III - em estrito cumprimento de dever legal ou no exercício regular de direito. Portanto, faz-se necessário, primeiramente, uma abordagem doutrinária conceituando-o.

Conforme preleciona Juarez Cirino dos Santos:

O estrito cumprimento de dever legal compreende os deveres de intervenção do funcionário na esfera privada para assegurar o cumprimento da lei ou de ordens de superiores da administração pública, que podem determinar a realização justificada de tipos legais, como a coação, privação de liberdade, violação de domicílio, lesão corporal etc. (JUARÉZ, 2000, p.187)

É habitual a aplicação desse instituto por agentes públicos, pois, são encarregados de autonomia em nome do interesse público, e se necessário podem restringir ou afetar direitos dos particulares e o motivo de não poderem ser 


\section{/ Fronteiras Interdisciplinares do Direito \\ Interdisciplinamy Boumdaries of I aw V1 N.12019}

responsabilizados é porque agirem no estrito cumprimento do dever legal, ou seja, não podendo ser responsabilizados civilmente.

Vale ressaltar ainda, a diferença entre o "estrito cumprimento" e o "dever legal", o primeiro diz respeito que esse cumprimento não pode passar dos limites legais, por isso o uso da palavra "estrito". Já o segundo remete à ideia de uma obrigação que advém de um ato normativo.

\subsection{EXERCÍCIO REGULAR DE DIREITO}

Como no estrito cumprimento do dever legal, este, também, não foi objeto de conceituação pelo legislador. Nesse sentido, Paulo José da Costa Júnior leciona:

O conceito de direito, empregado pelo inciso III do art. 23, compreende todos os tipos de direito subjetivo, pertençam eles a este ou àquele ramo do ordenamento jurídico - de direito penal, de outro ramo do direito público ou privado- podendo ainda tratar-se de norma codificada ou consuetudinária. (PAULO, 1991, p. 62)

Possui base legal novamente no Código civil art. 188, diz que: "I - Os praticados em legítima defesa ou no exercício regular de um direito reconhecido."

O exercício regular de um direito trata-se de um fato típico que tem sua ilicitude afastada pelo ordenamento jurídico, ou seja, a conduta é tipificada como crime, porém, por opção do legislador, passa a ser considerada como um direito de agir, perante uma permissão do ordenamento jurídico. Mas somente nesse âmbito, se por ventura, houver abuso desse direito e que não seja regular, caberão as devidas sanções por parte do agente que as cometeu, seja na esfera civil ou na penal.

Como exemplo de exercício regular de um direito está à correção aplicada pelos pais os seus filhos menores e as práticas esportivas violentas, desde que os atletas aplicam somente as regras previstas naquela determinada modalidade.

\section{Conclusão}

Através do presente trabalho foi possível verificar que a ocorrência de um ilícito penal sem dúvida pode trazer reflexos à esfera civil como também os diversos institutos da exclusão do ato ilícito, por cláusula expressa ou até mesmo por ausência de requisitos para se configurar a responsabilidade. 
Ao analisar o conteúdo acima e toda sua incidência evidencia-se que a ação civil ex delicto é eficiente na concretização de direitos e no acesso à justiça, que se opera no âmbito civil.

Constatou-se que não é possível falar-se nelas nas causas de excludentes de ilicitude, pois como conceituado pelo doutrinador Tourinho Filho a ação ex delicto é consequência oriunda do ato ilícito.

Porém, a responsabilidade civil parte de um pressuposto de que todo aquele que através de um ato lícito ou ilícito tem a obrigação de reparar, pois o dever jurídico originário de não causar dano deve ser respeitado, surgindo então, ao ofendido, nas hipóteses supracitadas, a possibilidade de reparação dos danos sofridos. 


\section{REFERÊNCIAS}

BRASIL. Constituição da República Federativa do Brasil: promulgada em 5 de outubro de 1988.

BRASIL. Decreto-Lei 2.848, de 07 de dezembro de 1940. Código Penal. Diário Oficial da União, Rio de Janeiro, 31 dez. 1940.

BRASIL. Lei 5.869, de 11 de janeiro de 1973. Institui o Código de Processo Civil. Diário Oficial da União, Brasília, 17 jan. 1973.

BRASIL. Lei n. 10.406, 10 de janeiro de 2002. Código Civil. Diário Oficial da União, Rio de Janeiro, 11 jan. 2002.

COSTA JÚNIOR, Paulo José da. Curso de direito penal - Parte geral. São Paulo: Saraiva, 1991.

GREGO, Rogério. Curso de direito penal: parte geral. 19. Ed. Rio de Janeiro: Impetus, 2017.

OLIVEIRA, Eugênio Pacellide. Curso de processo penal. $13^{\text {a }}$ edição, revisada e atualizada. Rio de Janeiro: Lumen Juris, 2010.

SANTOS, Juarez Cirino dos. Amoderna teoria do fato punível. Rio de Janeiro: Freitas Bastos, 2000.

TOLEDO, Francisco de Assis. Ilicitude penal e causas de sua exclusão. Rio de janeiro: Forense, 1994

TOURINHO FILHO, Fernando da Costa. Manual de processo penal. 13. Ed. - São Paulo: Saraiva, 2009. 